\title{
Prediction of Corrosion Expansion Cracking Time of Concrete Structures under Carbonization
}

\author{
Hailong Gan ${ }^{1, a^{*}}$ and Xiaoli Xie ${ }^{2, b}$ \\ ${ }^{1}$ Guangxi Technological College of Machinery and Electricity, Nanning, Guanxi, 530007, China \\ ${ }^{2}$ Guangxi University, Nanning, Guanxi, 530001, China \\ a617479986@qq.com
}

Keywords: Durability testing; The amount of steel bar corrosion; Carbonization; Cracking time

\begin{abstract}
In this paper, the durability test of concrete structures is carried out, and the test results are counted and analyzed. Based on the calculation model of the amount of steel bar corrosion in concrete, combined with the atmospheric environmental parameters and testing data of the service of the concrete structure, this paper analyzes and predicts the time of corrosion expansion cracking of concrete structures under carbonation, which provides a scientific basis for evaluating the service life of the bridge and the reinforcement and maintenance of the bridge.
\end{abstract}

\section{Introduction}

Concrete is a widely used building material all over the world. Since the reform and opening up, the number of concrete structures in China has been very large. However, a large number of concrete structures fail in advance for various reasons, which can not reach the service life of the design[1]. There are many reasons for this situation, but the main reason is the erosion and damage caused by atmospheric environment to the load-bearing members of the concrete structure, that is, durability failure. The carbonization of the concrete cover will cause the corrosion of the steel bar, and the corrosion of the steel bar is the most important factor causing the durability damage of the concrete structure[2]. The corrosion products after steel bar corrosion are 3-4 times the original volume, as shown in Fig.1. Corrosion products make the steel bar surrounding concrete receive expansion pressure, which leads to the longitudinal cracking of the concrete cover[3]. The cracks in the concrete structure surface will accelerate the corrosion of the steel bar, which leads to the failure of the structure. It is of great significance to study the corrosion cracking model of concrete structures to predict the remaining life of existing concrete structures.

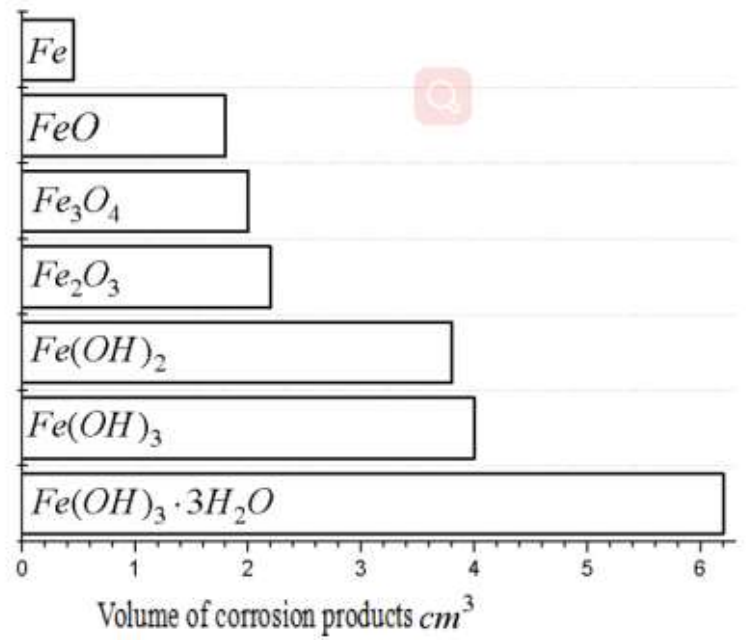

Figure 1. Corrosion product expansion diagram

\section{Prediction Model of the Amount of Steel Bar Corrosion}

Calculation Model of Corrosion Amount before Corrosion Expansion Cracking of Protective Layer. The calculation of the amount of steel bar corrosion in concrete is one of the core problems 
of durability assessment and life prediction of concrete structures[4]. Ditao Niu[5], a domestic scholar, has given the mathematical model formula(1-2), for the amount of the steel bar corrosion through the testing and data collection of the actual project. In this paper, the prediction formula is used to calculate the corrosion amount[6].

$$
\begin{aligned}
& \delta_{e 1}(t)=\lambda_{e 1}\left(t-t_{i}\right) \\
& \lambda_{e 1}=46 k_{c r} k_{c e} e^{0.04 T}(R H-0.45)^{2 / 3} c^{-1.35} f_{c u}{ }^{-1.83}
\end{aligned}
$$

In the formula: $\delta_{e 1}(t)$-The amount of steel bar corrosion before corrosion expansion cracking $(\mathrm{mm})$

$\lambda_{e 1}$ - Corrosion rate of steel bar before corrosion expansion cracking $(\mathrm{mm} / \mathrm{a})$

$k_{c r}$ - Correction coefficient of steel bar position

$k_{c e}$ _Correction coefficient of microenvironment conditions

$c$ - Thickness of concrete cover(mm)

$f_{c u}$ _Compressive strength of concrete cubes(MPa)

$T$-Structural service environment temperature(C)

$R H$-Structural service environment humidity(\%)

$t_{i}$ _-Initial time of steel bar corrosion(a)

$t$-Service life of structure(a)

Prediction of the Amount of Corrosion of Protective Layer during Corrosion Expansion Cracking. The formula for calculating the corrosion depth of steel bars is obtained by the Rordriguez $\mathrm{J}$ of Spain through rapid corrosion test[7]:

$$
\delta_{c r}=\left(83.8+7.4 c / d-22.6 f_{c u}\right) \times 10^{-3}
$$

In the formula: $\delta_{e 1}(t)$-The amount of steel bar corrosion before corrosion expansion $\operatorname{cracking}(\mathrm{mm})$

$c$ - is the same as the formula(2)

$d$-Diameter of steel bar(mm)

Through rapid corrosion test, the Tongji University gives the calculation formula of corrosion depth of steel bar when the concrete protection layer is rusty and cracked[8]:

$\delta_{c r}=0.008 c / d+0.00055 f_{c u}-0.002$

In the formula: $\delta_{e 1}(t)$-The amount of steel bar corrosion before corrosion expansion $\operatorname{cracking}(\mathrm{mm})$

$c, d$ - are the same as the formula(3) $\quad f_{c u}$-is the same as the formula(2)

Xiaobing Song[9] proposed a conclusion that the water cement ratio $\left(\frac{W}{C}\right)$ when the amount of steel bar corrosion in concrete and concrete materials are prepared is approximately linear.

Shanhua $\mathrm{Xu}$ and others[10]gave the suggested formula(5) of the amount of steel bar corrosion during corrosion expansion cracking of concrete. This paper uses this formula to calculate[6].

$$
\delta_{c r}=k_{c r s}\left(0.008 c / d+0.00055 f_{c u}+0.002\right)
$$

In the formula: $\delta_{c r}$ - The amount of steel bar corrosion during corrosion expansion cracking of concrete $(\mathrm{mm})$

$k_{c r s}$ - Influence coefficient of the steel bar position, angular part selects 1 and non angular part selects 1.35 .

$c$-Concrete strength $\quad d$-Diameter of steel bar

Prediction of Corrosion Expansion Cracking Time of Protective Layer. After calculating the 
$\delta_{c r}$ and $\lambda_{e 1}$, the time point of corrosion expansion cracking of concrete cover can be calculated according to the formula(6):

$$
t_{c r}=\frac{\delta_{c r}}{\lambda_{e 1}}
$$

In the formula: $t_{c r}-$ Corrosion expansion cracking time of concrete cover(a)

\section{Engineering Application Example}

Nanning Youai overpass No. 2 is located at the intersection of the North Circular Road and Youai Road, and underneath passes through the North Ring Line. The plane intersection coordinate of it and Youai overpass No. 1 is $\mathrm{X}=2528723.803, \mathrm{Y}=530702.551$. The length of the bridge is 126 meters, the width is 23.7 meters, it is a total of 4 spans, and the total area is $2986.2 \mathrm{~m}^{2}$. The bridge is located on the circular curve of the radius $\mathrm{R}=1100$ and $\mathrm{T}=321.66 \mathrm{~m}$. There is no central separation belt in the bridge. Load standard: City A level, and the earthquake intensity is 6 degree. The bridge span arrangement is $28+35+35+28$ meters, the width of traffic lane the bridge(center line of road) is 22.5 meters, the cross section is a two-way slope, and the slope is $1.5 \%$. The bridge design load vehicle -over 20, Trailer - 120.

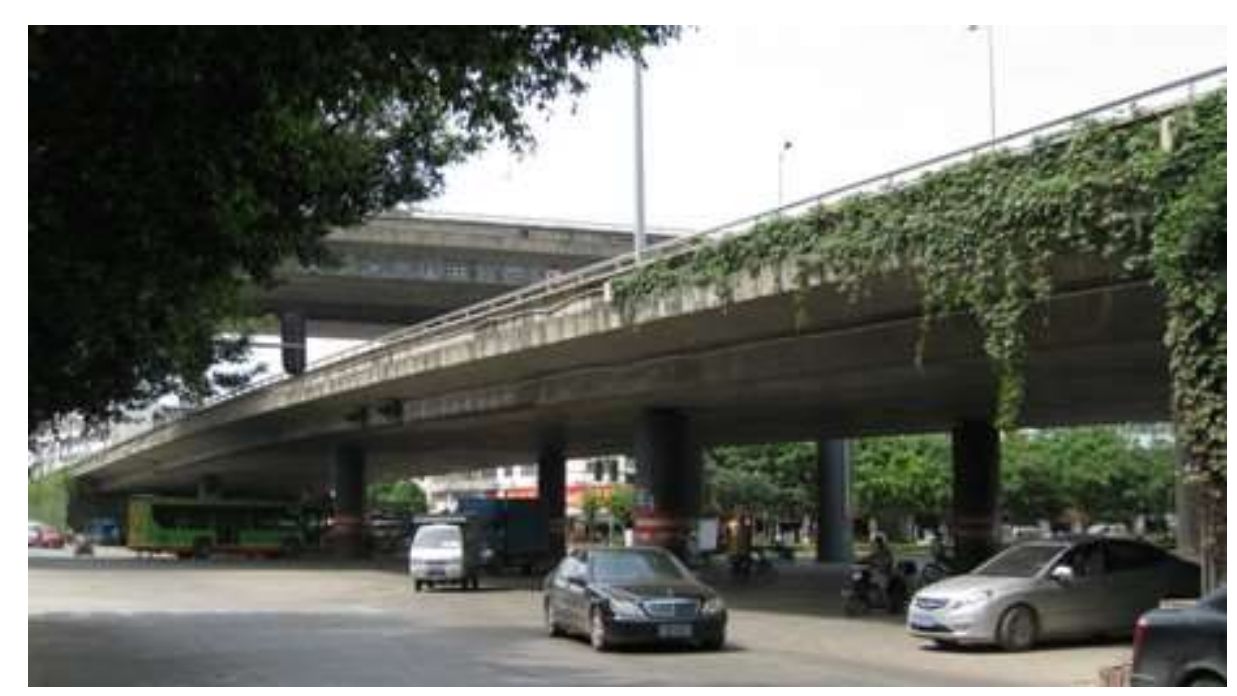

Figure 2. Overall appearance of bridge structure

Investigation of concrete diseases. The function of the important parts of the Youai overpass No. 2 is good and the support is basically intact. The bridge deck pavement is basically intact. The appearance of the protective fence of two sides is normal, and there are no diseases, such as corrosion, exposed reinforcing steel, loosening and dislocation. The drain pipe is damaged. There is a bruise mark by cars on the bottom of the box beam. The information sign of the pier is broken. There are water leaks on both sides of the bridge abutment. There is a crack in the south bridge abutment and the width of the seam is larger.

Nondestructive Testing of Concrete Strength. In literature 5, a large number of experiments show that the strength of concrete has a significant effect on the loss rate of steel section. With the increase of concrete strength, the loss rate of cross section decreases significantly. For the pier stud and longitudinal beam of the bridge, the ultrasonic- rebound combined method is used to detect the concrete strength. For the bridge abutment and cap beam, the rebound method is used to detect the concrete strength. The test results of the concrete strength of the main bridge members are shown in Table 1. 
Table 1 Test results of concrete strength of main bridge members

\begin{tabular}{cccccc}
\hline $\begin{array}{c}\text { Compone } \\
\text { nt name }\end{array}$ & $\begin{array}{c}\text { Sample } \\
\text { number }\end{array}$ & $\begin{array}{c}\text { Average } \\
\text { value(Mpa) }\end{array}$ & $\begin{array}{c}\text { Standard } \\
\text { deviation(Mp } \\
\text { a) }\end{array}$ & $\begin{array}{c}\text { Coefficient } \\
\text { of variation }\end{array}$ & $\begin{array}{c}\text { Probability } \\
\text { distribution }\end{array}$ \\
\hline $\begin{array}{c}\text { Bridge } \\
\text { abutment }\end{array}$ & 20 & 45.65 & 1.7 & 0.04 & $\begin{array}{c}\text { Normal } \\
\text { distribution } \\
\text { Pier stud }\end{array}$ \\
42 & 61.5 & 3.2 & 0.03 & $\begin{array}{c}\text { Normal } \\
\text { distribution } \\
\text { Normal }\end{array}$ \\
Cap beam & 22 & 43.65 & 4.5 & 0.06 & $\begin{array}{c}\text { distribution } \\
\text { Normal } \\
\text { distribution }\end{array}$ \\
$\begin{array}{c}\text { Longitudi } \\
\text { nal beam }\end{array}$ & 66 & 56.6 & 2.3 & 0.07 & \\
\hline
\end{tabular}

Analysis of Carbonization Depth of Concrete. The carbonization of concrete cover is the most important factor to cause corrosion of steel bar, so it is particularly important to detect the carbonization depth of concrete cover. The detection of concrete carbonization uses the method of dropping the phenolphthalein reagent. Random sampling method is used to carry out the random sampling detection for the beam of bridge. The detection of the beam is to randomly detect 24 points at the bottom of the selected beam. The measured carbonation depth of concrete is shown in Fig.3.

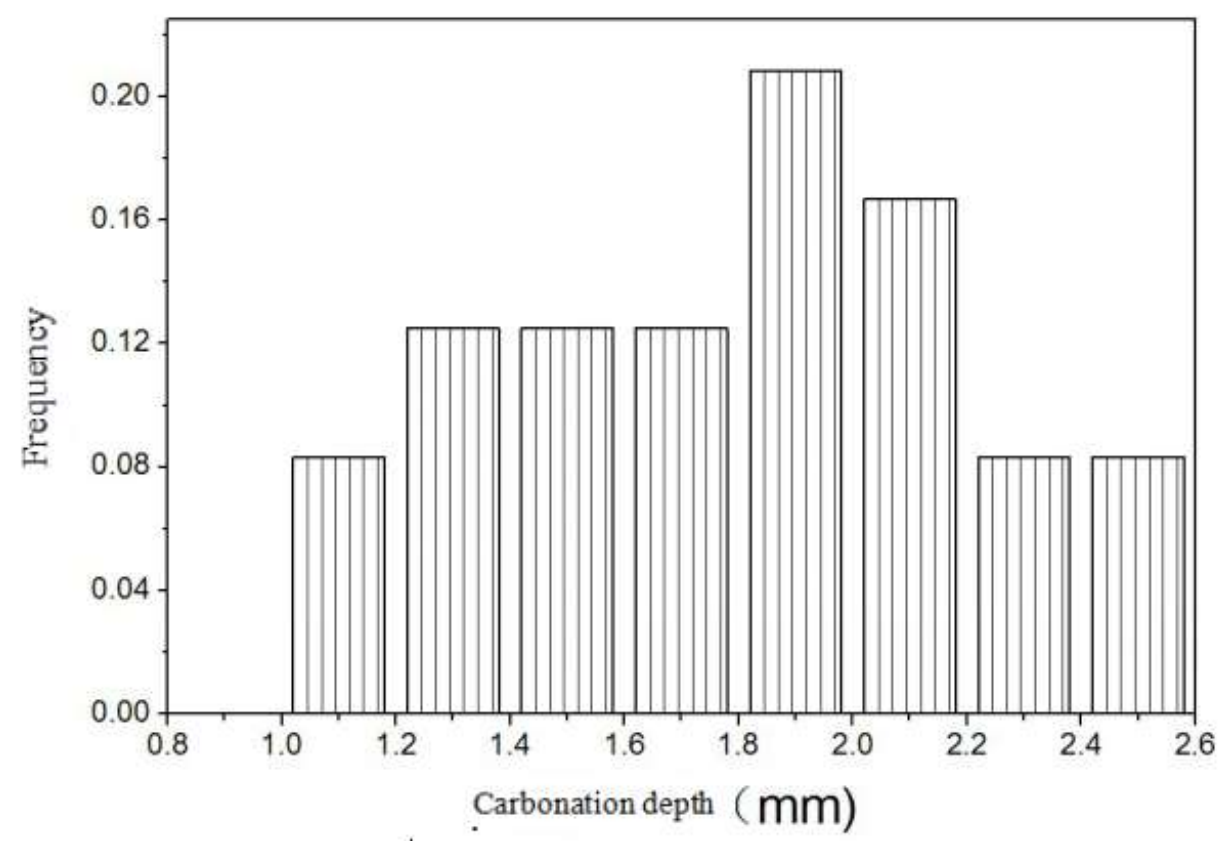

Figure 3. Columnar distribution diagram of concrete carbonization depth of main beam

Thickness Analysis of Concrete Cover. In literature 5, a large number of experiments show that the thickness of concrete cover has a significant influence on the loss rate of steel section. With the increase of the thickness of the protective layer, the loss rate of the cross section decreases significantly. The random sampling method is used to carry out the random sampling detection for the beam of the bridge. The detection of the beam is to detect 20 points at the bottom of the selected beam. The measured thickness value of the concrete cover is shown in Fig.4. 


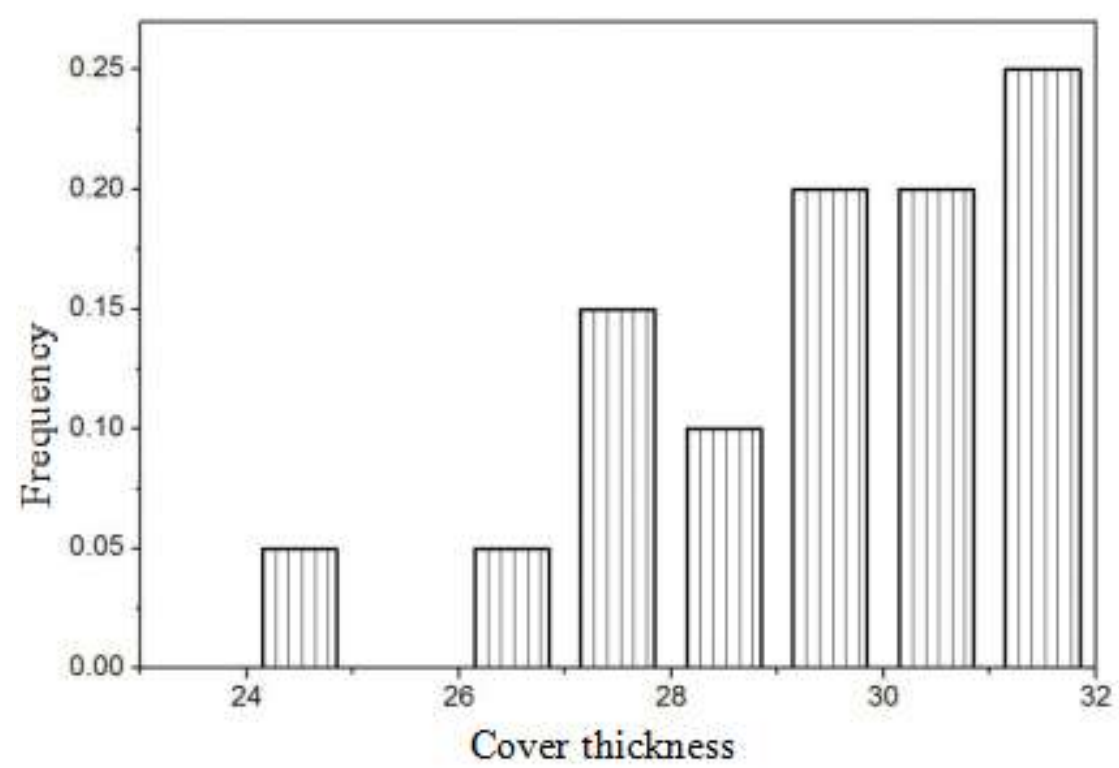

Figure 4. Columnar distribution diagram of the thickness of concrete cover of main beam

Analysis of Chloride Content in Concrete. In the durability loss of a large number of reinforced concrete structures, the loss caused by the diffusion of chloride ion can be said to be the first. Chlorine ion mainly destroys the alkaline environment of concrete, thus the $\mathrm{pH}$ value of concrete is obviously decreased and the corrosion process is accelerated. The chloride ion itself obviously reduces the resistance of the concrete and improves the efficiency of the corroded battery. The method for the determination of the content of chloride ion is to detect 102 points randomly on the main beam, of which $5 \mathrm{~mm}$ depth and $25 \mathrm{~mm}$ depth are 51 points each. The chemical analysis is carried out in the laboratory after core-drilling and taking the powder. The content distribution curve of the measured chlorine ion is shown in Fig.5-6. According to the evaluation standard of the influence degree of the content of chloride ion on the corrosion of steel bar, when the chloride content is less than $0.15 \%$, the probability of steel bar corrosion in concrete is very small.

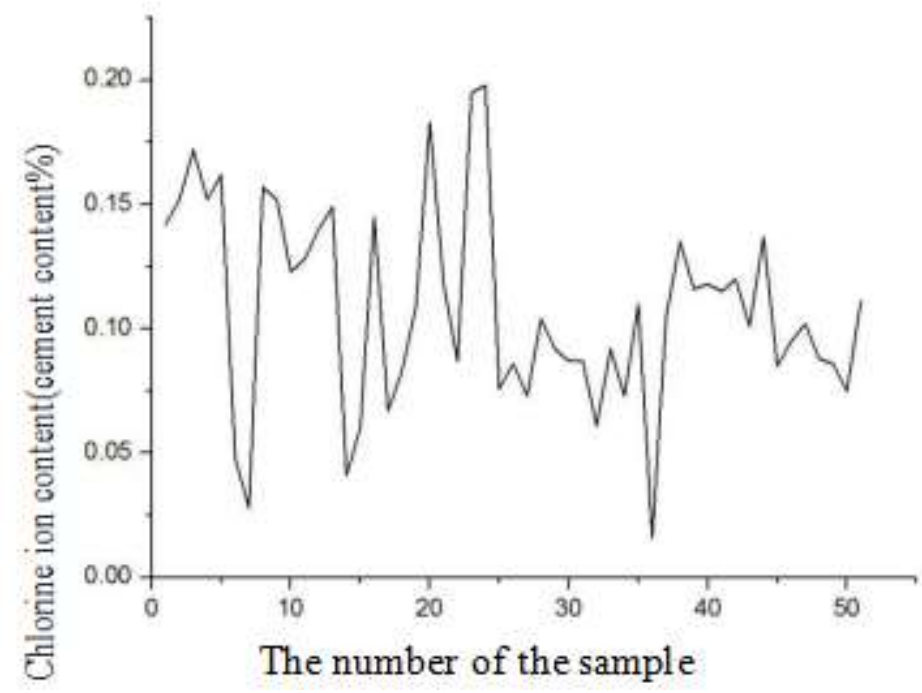

Figure 5. Content distribution curve of $5 \mathrm{~mm}$ depth of chloride ion 


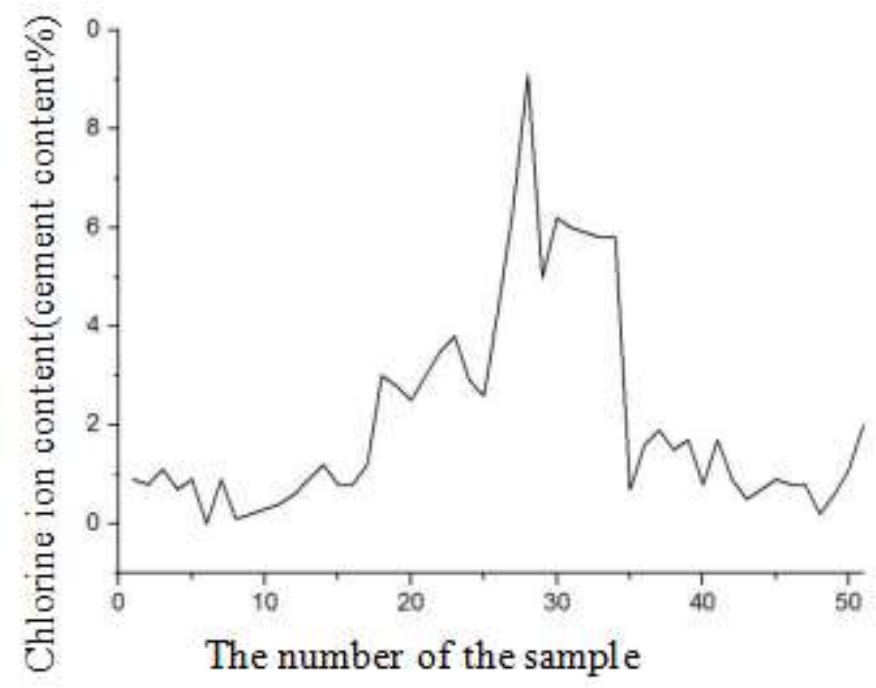

Figure 6 Content distribution curve of $25 \mathrm{~mm}$ depth of chloride ion

\section{Prediction of Corrosion Expansion Cracking Time of Concrete Structure}

The quality of concrete structure, construction technology, atmospheric environment and material performance all have randomness, so that the amount of corrosion of reinforced concrete structure also has greater randomness. So the time point of the corrosion expansion cracking of the concrete structure protection layer is actually a random variable. The measured durability data of Youai overpass No.2 is introduced into the formula (1) - (6), and the distribution rule of the time point of corrosion expansion cracking of the concrete cover of the main beam of the bridge can be obtained, as shown in Fig.7 and Fig.8.

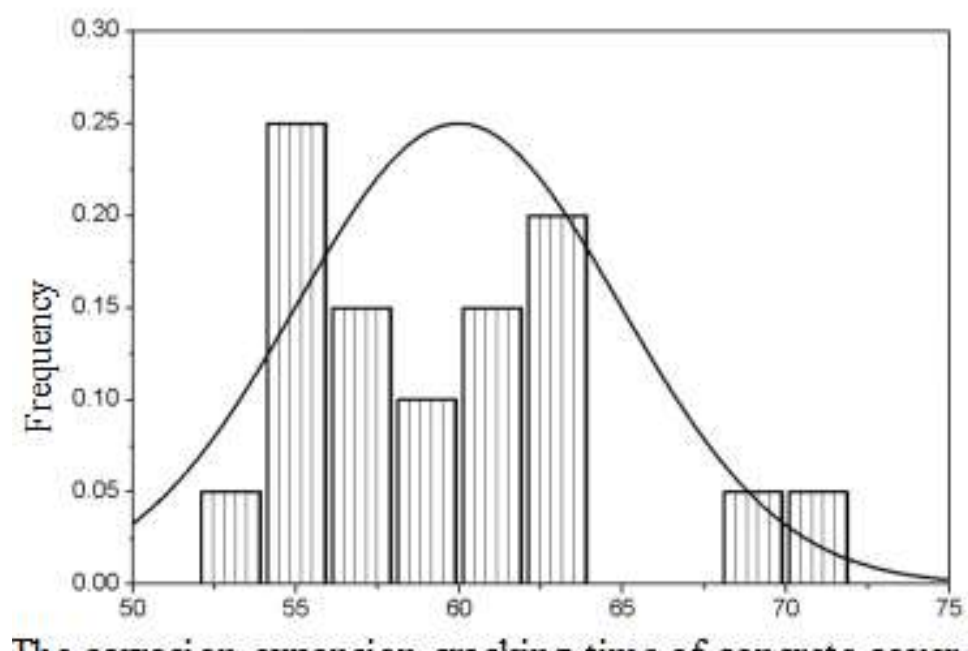

The corrosion expansion cracking time of concrete cover

Figure 7 Corrosion expansion cracking time columnar distribution of concrete cover of main beam 


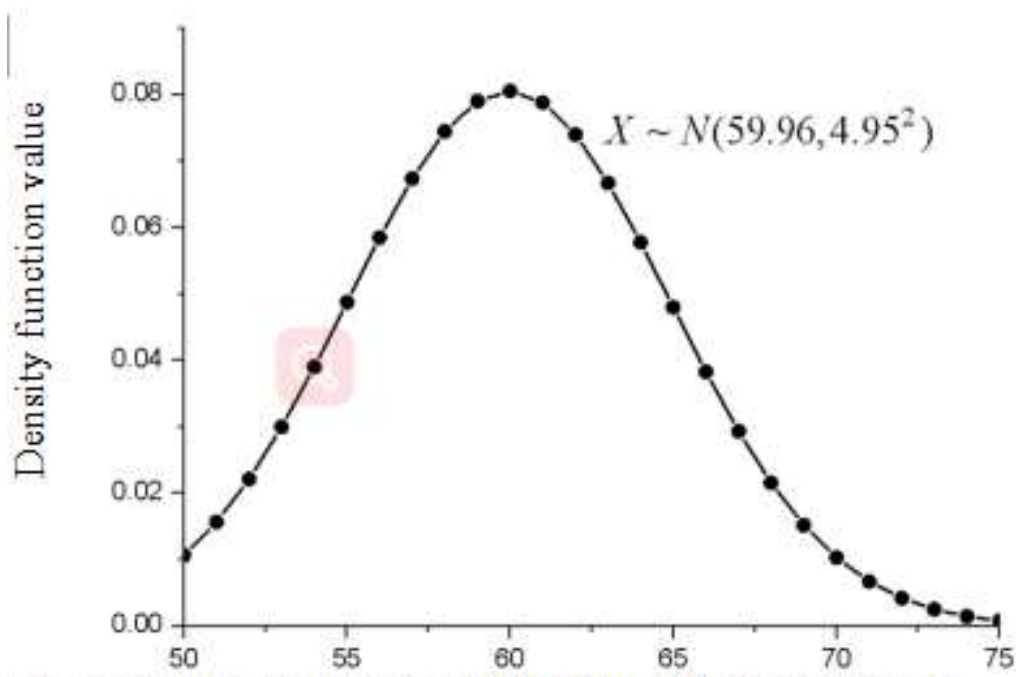

The corrosion expansion cracking time of concrete cover

Figure 8. The time density function of the corrosion expansion cracking of the concrete cover of the main beam

\section{Conclusion}

In this paper, the durability test of Youai overpass No. 2 is carried out, and the relative durability data of chlorine ion content in concrete are collected. Combined with the prediction model of the corrosion expansion cracking of concrete, the time distribution probability of the corrosion expansion cracking of the main beam concrete of the Youai overpass No.2 is calculated. The main conclusions are as follows:

The first one is that the concrete strength of the main load-bearing members of the bridge meets the design requirements.

The second one is that the thickness of the concrete cover of the main beam is random, and its thickness detection value obeys the normal distribution better.

The third one is that in the detection sample of the content of chloride ion in the concrete of the main beam, $96.17 \%$ sample chloride concentration is not up to $0.15 \%$. It is considered that there is no obvious rust trace in the steel bar in the main beam concrete.

The fourth one is that the time of cracking due to the steel bar corrosion of the concrete cover of the main beam has the characteristic of random distribution, and the whole doesn't reject the normal distribution. The density function of the time distribution of corrosion expansion cracking of concrete is shown in Fig.8. From it, we can calculate that the probability of the corrosion expansion cracking of the concrete cover of the main beam of the Youai overpass No. 2 for 55 to 65 years is $78.26 \%$.

\section{Acknowledgements}

Scientific research funding project of the University of Education Department of Guangxi. Project number: 201106LX665.

\section{References}

[1] Y.S.Zhao, J.Xu and Z.X.Du: Reinforcement Measures of Concrete Sructures Subjected to Chloride Ion Corrosion[J], Architecture Technology, 2008, (05): 362-363.(In Chinese)

[2] C.H.Lin: Analysis of the Thickness of Reinforced Concrete Protective Layer Based on Carbonization Mechanism[J], China High Technology Enterprises, 2008, (22): 190-191.(In Chinese)

[3] Y.J.Mu, Y.S.Yuan and Y.S.Ji: Analysis Method of Concrete Stress Based on Corrosion and 
Expansion of Steel Bar[J], Journal of Huaihai Institute of Technology(Natural Sciences Edition), 2006, (01): 66-70.(In Chinese)

[4] S.Z.Lin, Y.F.Li and W.Su: Reliability Analysis of Active Structure Based on Durability[J], Journal of Baotou University of Iron and Steel Technology, 2006, (01): 81-84.(In Chinese)

[5] H.Liu, J.T.Yao and D.T.Niu: Durability Design Method of Reinforced Concrete Structure Based on Corrosion Expansion Cracking Life Criterion[J], Journal of Xi'an University of Architecture \& Technology, 2009, (01): 25-31.(In Chinese)

[6] H.L.Gan and X.L.Xie: Prediction Method of Corrosion Expansion Cracking Time in Protective Layer of Active Concrete Structure[J], Western China Communications Science and Technology, 2012, (04): 36-40.(In Chinese)

[7] X.H.Wu: Evaluation Method of Load-Bearing Capacity of Reinforced Concrete Flexural Members in Active Harbor Wharf[J], Port and Waterway Engineering, 2006, (08): 49-52. (In Chinese)

[8] X.H.Wu: Evaluation Method of Load-Bearing Capacity of Reinforced Concrete Flexural Members in Service[J], Sichuan Building Science, 2007, (02): 55-58.(In Chinese)

[9] X.B.Song and X.L Liu: Process Control of Corrosion Rate of Steel Bar in Concrete[J], Industrial Construction, 2000, (06): 53-56.(In Chinese)

[10] S.H.Xu, D.T.Niu and Q.L.Wang: Corrosion of Steel Bars in Concrete under Atmospheric Conditions[J], Architecture Technology, 2003, (04): 267-269.(In Chinese) 